\title{
EVIDENCE BASED UPDATE ON THE MANAGEMENT OF ACNE
}

Jane Ravenscroft

Arch Dis Child Educ Pract Ed 2005;90:ep98-ep101. doi: 10.1136/adc.2004.071183

Correspondence to: Jane Ravenscroft, Department of Dermatology, Queen's Medical Centre, Nottingham NG7 2UH, UK; jane. ravenscroff@qmc.nhs.uk
$\Lambda$ cne is an extremely common condition, affecting up to $80 \%$ of adolescents. Many cases are mild and may be considered "physiological", but others can be very severe and lead to permanent scarring. Paediatricians will frequently encounter acne in their practice, and have an important role in identifying and advising patients who require treatment.

This review focuses on the practical management of acne from a paediatric perspective, with an emphasis on relating treatment decisions to currently available evidence. Many clinical trials of acne treatment have been carried out in the last 25 years, but they are of variable quality. Hence, there are grey areas, where treatment has to be guided by consensus opinion or clinical experience until better evidence is available.

\section{CLINICAL FEATURES AND AETIOLOGY}

Acne is a disease of pilosebaceous follicles. Under the influence of androgens, usually around puberty, the sebaceous glands enlarge and produce excess sebum. At the same time, keratinocytes in the sebaceous duct proliferate and cause blockage. These events lead to comedone formation. As a secondary event, Propionibacterium acnes ( $P$ acnes) colonise the comedones causing inflammation, which leads to papules and pustules.

Clinically, acne usually affects the face first, with the back and chest affected in more severe cases. The lesions seen are blackheads (open comedones), whiteheads (closed comedones), papules, pustules and sometimes nodules, cysts, and scars.

\section{TREATMENT}

Treatment is influenced by the type of lesions, severity, sex and age of patient, psychological impact of the disease, and presence of scarring.

In exceptional circumstances where there is abnormal androgen production, or an external cause, treatment is directed to the underlying cause.

All acne treatments take up to 12 weeks to reach maximum benefit, and should usually be continued for several months. Education regarding the natural history of acne and expectations of treatment will improve compliance.

\section{TREATMENT OF MILD ACNE}

Case history A

Michael, who is 13, has been attending your clinic with an unrelated problem. He is on no medication. Mum mentions that he is getting a few teenage spots on his forehead and nose, and wants to know whether cutting out chocolate and washing more frequently would help. Also, is it worth buying acne preparations from the chemist for Michael to use?

Diet

Although it is widely believed that foods such as chocolate and sweets aggravate acne, there is no evidence to support this. In a study of chocolate ingestion among acne sufferers, acne was unaffected in the majority, improved in a few, and worsened in a few. ${ }^{1}$ Acne sufferers should be reassured that a normal healthy diet is best.

\section{Skin care}

There is no evidence that lack of washing is associated with acne, or that frequent washing improves it. Acne patients should wash their skin daily using warm water \pm ordinary soap. Antibacterial soaps, which contain agents such as chlorhexidine and triclosan, do not affect $P$ acnes. Abrasives should be avoided as they can aggravate inflammation. Make up and moisturisers, if needed, should be oil-free and non-comedogenic. ${ }^{2}$ 


\section{Topical salicylic acid}

Many acne washes and topical preparations on sale to the public contain salicylic acid as the active ingredient. This is an anti-keratolytic with some anti-comedone effects, which is widely considered to be of some effect in mild acne, but there is a lack of evidence of efficacy from randomised controlled trials.

\section{Topical benzoyl peroxide}

Benzoyl peroxide is a cheap, safe, and effective treatment for acne, which can be bought "over the counter" in the UK. It is a powerful antimicrobial agent that rapidly destroys $P$ acnes. This has a secondary effect of reducing comedones. It has been shown to be more effective than topical antibiotics in several studies, ${ }^{3}$ and is not affected by bacterial resistance. A recent randomised controlled trial of five antimicrobial regimens for treatment of mild to moderate inflammatory facial acne in the community showed moderate or greater improvement at 18 weeks in $60 \%$ of patients on benzoyl peroxide alone, and concluded it was the most cost effective treatment. ${ }^{4}$

Benzoyl peroxide is available in a variety of formulations and concentrations ranging from $1-10 \%$. Treatment should be applied once or twice daily to the entire area affected by acne. The main side effect of benzoyl peroxide is skin irritation and dryness, which can be severe enough to preclude use. Patients also need to be warned about bleaching of clothes.

Benzoyl peroxide washes can be effective if large areas of coverage are needed, and are less irritant than "leave on" preparations.

\section{TREATMENT OF MODERATE ACNE \\ Case A (continued)}

At annual review one year later, aged 14, Michael's acne is much worse. He has a lot of blackheads and whiteheads on his face, and many inflamed lesions on his back and chest. He has been using benzoyl peroxide $5 \%$ gel on his face on most days but this is not really helping. What would you do next?

A more detailed history should be taken. Some drugs have been associated with exacerbation of acne (table 1). A strong family history of acne is a predictor of more severe disease.

If no exacerbating factors are identified, there is a choice of treatments that can be used. All of these are best used in combination with benzoyl peroxide, if tolerated.

$\begin{aligned} & \text { Table } 1 \text { Drug and external factors reported to cause } \\
& \text { acne/acneiform eruptions }\end{aligned}$
\begin{tabular}{ll}
\hline Hormones and steroids & External factors \\
\hline Androgens & Cosmetics \\
Anabolic steroids & Pomades \\
Oral and topical steroids & Machine oils and tars \\
Gonadotropins & Mechanical trauma, e.g. head bands \\
Epileptic drugs & \\
Phenobarbital & \\
Phenytoin & \\
Antituberculous drugs & \\
Isoniazid & \\
Rifampicin & \\
\hline
\end{tabular}

Topical retinoids

Randomised controlled studies have shown that retinoids reduce comedones and inflammatory lesions by $40-80 \%{ }^{2}$ Many formulations and strengths of retinoids are available on prescription. The most widely used is tretinoin, which is available in strengths of $0.01 \%$ and $0.025 \%$.

All retinoids cause skin irritation, which may preclude use in some patients. This is less pronounced with second generation retinoids-for example, adapalene-and can be reduced by techniques such as alternate day application or short contact use-that is, washed off after one hour.

Topical retinoids may be used alone, but are more effective when combined with a topical antibacterial, either benzoyl

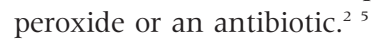

\section{Topical antibiotics}

Clindamycin and erythromycin are available in topical formulations and are effective against inflammatory acne. ${ }^{6}$ They are not generally recommended as monotherapy because of (a) slow onset of action, (b) limited efficacy against non-inflammatory lesions, and (c) potential for emergence of resistant $P$ acnes and Staphylococcus aureus. Emergence of resistance is reduced by limiting treatment to eight weeks at a time, and combining with benzoyl peroxide. ${ }^{2}$

\section{Topical azelaic acid}

Azelaic acid cream $20 \%$ is a naturally occurring dicarboxylic acid with antibacterial and anti-keratinising effects. It has been reported to have similar efficacy to benzoyl peroxide and retinoids in reducing inflammatory lesions and comedones, ${ }^{7}$ but is less widely used. It causes little skin irritancy, and is therefore particularly useful for patients who cannot tolerate benzoyl peroxide or retinoids.

\section{Oral antibiotics}

Oral antibiotics were the mainstay of acne treatment for many years.

They are particularly useful when large areas of the body are involved with acne, or when patients cannot tolerate or dislike topical therapy. ${ }^{8}$

Tetracyclines (tetracycline, oxytetracycline, minocycline, lymecycline, and doxycycline), macrolides, trimethoprim, clindamycin, and quinolones are all effective at eliminating $P$ acnes, and reducing inflammatory lesions in acne. Oxytetracycline should generally be the first choice of oral antibiotic in a dose of $1 \mathrm{~g}$ per day. A Cochrane systematic review ${ }^{9}$ has concluded that there is no justification for using minocycline first line because of lack of evidence for greater efficacy, concerns about safety, and higher cost. There may be some justification for using other second generation tetracyclines-for example, lymecycline-because it is taken once daily, and absorption is unaffected by food.

Tetracyclines are contraindicated in children under 12 years because they cause staining of developing teeth.

Antibiotic resistance of $P$ acnes is an increasing problem. Up to $50 \%$ of patients carry $P$ acnes resistant to erythromycin, and up to $20 \%$ resistant to tetracycline. This can be associated with therapeutic failure.

In an attempt to reduce resistance, it is recommended that antibiotics should be used for no more than six months at a time, and that benzoyl peroxide is used concurrently where possible. The addition of a retinoid may be beneficial to reduce non-inflamed lesions. ${ }^{9}$ 
Table 2 Hormonal investigations for acne

\begin{tabular}{|c|c|}
\hline Investigation & Possible cause of elevation \\
\hline Total and free testosterone & $\begin{array}{l}\text { Polycystic ovarian syndrome } \\
\text { Rarely, ovarian tumours }\end{array}$ \\
\hline $\begin{array}{l}\text { Serum dehydroepiandosterone } \\
\text { (DHEAS) }\end{array}$ & $\begin{array}{l}\text { Adrenal tumour or congenital adrenal } \\
\text { hyperplasia }\end{array}$ \\
\hline $\begin{array}{l}\text { Lutenising hormone/follicular } \\
\text { stimulating hormone (LH/FSH) } \\
\text { ratio }\end{array}$ & Polycystic ovarian syndrome \\
\hline 17-hydroxyprogesterone & Congenital adrenal hyperplasia \\
\hline Prolactin & Hyperprolactinaemia \\
\hline 24 hour urinary free cortisol & Cushing's disease or syndrome \\
\hline
\end{tabular}

A recent randomised controlled trial has shown that topical benzoyl peroxide and topical benzoyl peroxide/erythromycin combinations are similar in efficacy to oral oxytetracycline and minocycline. ${ }^{4}$ This, and increasing concerns about bacterial resistance, put into question the widespread use of oral antibiotics for acne.

\section{TREATMENT OF SEVERE ACNE \\ Case B}

Mandy, who is 15 years old, has been under your care with asthma for several years. She attends with her mother who is very concerned because Mandy has stopped going out because she is self conscious about her spots. Examination of Mandy's skin reveals multiple pustules and comedones on the face, back, and chest. There are also some nodules and cysts on her cheeks. What advice would you give?

A more detailed history is needed. Mandy's activities are being affected by her acne. Has she any other features of depression? Is there any evidence of scarring? Are there any features of androgen excess? Are corticosteroid drugs exacerbating her acne? Is Mandy sexually active?

Menstrual irregularities, hirsuitism, or signs of hyperandrogenism should prompt hormonal investigation (table 2). Effort should be made to reduce oral steroids if possible. Technique of inhaled steroid should be checked as poor technique can lead to perioral acne.

Treatment needs to be aggressive in this situation, to restore self confidence and prevent scarring.

Initially, topical treatment \pm oral antibiotic should be started as for moderate acne. Hormonal treatment should be discussed. In the presence of severe acne, referral to a dermatologist is recommended for consideration of oral isotretinoin therapy

\section{Hormonal treatment}

Hormonal treatment can be an excellent option for females, especially if oral contraception is desirable. ${ }^{2}$ It can be effective even if circulating androgen values are normal, because there may be increased sensitivity of the sebaceous follicle to a normal concentration of androgens. Relative contraindications include a history of smoking, family history of venous thromboembolism, and obesity.

Options for hormonal therapy are oestrogens or antiandrogens. In practice, in the UK, the most commonly used agent is Dianette combined oral contraceptive pill (COC). This is a combination of cyproterone acetate $2 \mathrm{mg}$ (an antiandrogen) with ethinylestradiol $35 \mu \mathrm{g}$. Improvement in acne may be expected in $75-90 \%$ of patients with reduction in both comedones and inflammatory lesions. ${ }^{10}$ Some other COCs have also been shown to be of benefit in acne. ${ }^{11}$

Hormonal treatment is generally used in combination with topical therapy. It is also helpful in patients where isotretinoin is being considered, because of its contraceptive effect.

\section{Isotretinoin}

Isotretinoin, an oral retinoid, is indicated for severe nodular or scarring acne. It may also be used for moderate acne, which is unresponsive to other treatments, rapidly relapsing, or associated with high psychological distress. ${ }^{2}$

Isotretinoin is extremely effective- a single course of $0.5-1 \mathrm{mg} / \mathrm{kg} / \mathrm{day}$ for $4-6$ months will achieve clearance in most cases of severe acne. Eighty per cent of patients will not need a further course. Isotretinoin is generally used as monotherapy.

\section{Adverse effects of isotretinoin}

Isotretinoin is associated with potentially serious side effects, most notably teratogenicity and mood changes (table 3). It can only be prescribed from hospital, and there are strict guidelines governing its use. The teratogenic effects are well documented and include central nervous system, central face, and cardiovascular abnormalities. ${ }^{12}$ From 2005, all patients at potential risk of pregnancy-that is, females of child bearing age-must be enrolled in a pregnancy prevention plan which involves at least one form of contraception, negative pregnancy tests pre-treatment and monthly during treatment, and isotretinoin prescriptions for only one month of treatment at a time. ${ }^{13}$ This has considerable implications for resources in dermatology departments, and will inevitably result in reduced use of isotretinoin.

The situation regarding mood changes is less clear. Irritability, depression, and suicide have been reported in case reports and small studies since 1983. However, a review of the evidence by the retinoid working party on behalf of the British Association of Dermatologists concludes that suggestions of mood changes are currently unproven. ${ }^{13}$ Until more evidence is available, it is recommended that all patients given isotretinoin are questioned regarding psychiatric history and psychological symptoms, before and during treatment

\section{INFANTILE ACNE}

Case C

A 12 month old infant is referred for investigation of recurrent skin infections on the face. On examination, there are papules and pustules on the central cheeks

Table 3 Side effects of isotretinoin

\section{Dose related and predictable}

Dryness of skin and mucous membranes including nose, eyes, and lips Of particular concern

Teratogenicity, during treatment and for 6 weeks after stopping Mood change-highly publicised, unproven, but cause for concern Uncommon

Facial erythema, eczema, hair loss, and photosensitivity Myalgia and arthralgia Abnormalities of liver function Elevation of triglycerides and cholesterol values Bacterial overgrowth, particularly Staphylococcus aureus Benign intracranial hypertension 
Table 4 Summary of treatments for acne

\begin{tabular}{llll}
\hline & Mild & Moderate & Severe \\
\hline First choice & Benzoyl peroxide (BPO) & $\begin{array}{l}\text { Comedone predominant } \\
\text { Benzoyl peroxide + topical retinoid } \\
\text { Inflammatory predominant } \\
\text { Benzoyl peroxide + topical antibiotic }\end{array}$ & Oral isotretinoin \\
Alternatives & $\begin{array}{l}\text { Topical retinoid } \\
\text { Azelaic acid } \\
\text { Salicylic acid }\end{array}$ & $\begin{array}{l}\text { Oral antibiotic }+ \text { BPO } \\
\text { Azelaic acid } \\
\text { Consider hormonal therapy for females }\end{array}$ & As for moderate acne \\
& & & \\
\hline
\end{tabular}

which mum says have been present since three months, and are getting worse. What is the likely diagnosis, and what are your treatment options?

The likely diagnosis is infantile acne. This is a rare form of acne, probably due to transplacental stimulation of adrenal androgens. ${ }^{14}$ It presents between $3-18$ months of age and is more common in boys. Inflammatory lesions are most common, but comedones can occur. Infantile acne can last for several years, and is occasionally severe enough to cause scarring.

Mild disease responds to topical treatment with benzoyl peroxide, antibiotics, or retinoids. Oral erythromycin may be used. Oral tetracyclines are contraindicated in infants. Severe cases have been successfully treated with oral isotretinoin. ${ }^{15}$

\section{COMPLEMENTARY AND PHYSICAL THERAPIES \\ Case D}

Sally is 12 years old and has moderate acne. Sally's father would like to know if any complementary or physical therapies are worth exploring as Sally dislikes creams, and father is worried about side effects from antibiotics. What is your advice?

A range of complementary therapies has been tried for acne. At the present time there is insufficient evidence to recommend them in place of standard therapy.

\section{Zinc}

A randomised comparative study showed that $31 \%$ of patients achieved at least two thirds reductions of inflammatory lesions with oral zinc $30 \mathrm{mg}$ daily after 90 days, compared with $63 \%$ for minocycline. ${ }^{16}$

\section{Comedone extraction and cautery}

Comedone extraction can provide immediate benefit, but risks of incomplete extraction and tissue damage outweigh benefits. ${ }^{2}$

Light cautery to large comedones, which have not responded to conventional therapy, is sometimes used by dermatologists as an adjunct therapy in severe acne. ${ }^{14}$

\section{Light and laser therapy}

Many patients report that sunlight is beneficial for their acne, probably through antibacterial effects. Ultraviolet light regimens are no longer recommended because of concern about side effects, and reports that prolonged use can make acne worse.
There has been recent interest in photodynamic and laser therapy for acne, with promising early results from a study of pulsed-dye laser. ${ }^{17}$

\section{SUMMARY}

Acne is a common condition, which can be managed very effectively with a range of treatments. Treatment is aimed at improving appearance, discomfort, and psychological well being; and preventing scarring. A summary of recommended treatment options is given in table 4 .

\section{RELEVANT LINKS}

- Acne Support group: www.stopspots.org

- British Association of Dermatologists: www.bad.org.uk Statement of competing interests: I have no competing interests to declare

\section{REFERENCES}

Fulton JE, Plewig G, Kligman AM. Effect of chocolate on acne vulgaris. JAMA 1969;210:2071-4.

2 Gollnick H, Cunliffe WJ. Management of acne. A report from a global alliance to improve outcomes in acne. J Am Acad Dermatol 2003;49(suppl):S1-37.

3 Burke B, Eady EA, Cunliffe WJ. Benzoyl peroxide versus topical erythromycin in the treatment of acne vulgaris. Br J Dermatol 1983;108:199-204.

4 Ozolins M, Eady EA, Avery AJ, et al. Comparison of five antimicrobial regimens for treatment of mild to moderate inflammatory facial acne vulgaris in the community: randomised controlled trial. Lancet 2004;364:2188-95.

5 Mills $\mathrm{OH}$, Kligman AM. Treatment of acne vulgaris with topically applied erythromycin and tretinoin. Acta Dermatovenereol 1978;58:555-7.

6 Lehman HP, Andrews JS, Robinson KA, et al. Management of acne. Database of abstracts of reviews of effects 2005, issue 2

7 Gaupe K, Cunliffe WJ, Gollnick HP, et al. Efficacy and safety of topical azelaic acid $(20 \% \mathrm{cream})$ : an overview of results from European clinical trials and experimental reports. Cutis 1996;57(suppl):20-35.

8 Dreno B, Bettoli V, Ochsendorf F, et al. European guidelines on the use of oral antibiotics for acne. Eur J Dermatol 2004;14:391-9.

9 Garner SE, Eady EA, Popescu C, et al. Minocycline for acne vulgaris: efficacy and safety. The Cochrane Database of Systematic Reviews 2003, issue 1.

10 Miller JA, Wojnarowska FT, Dowd PM. Antiandrogen treatment in women with acne: a controlled trial. Br J Dermatol 1986;114:705-16.

11 Arowojolu AO, Gallo MF, Grimes DA, et al. Combined oral contraceptive pills for the treatment of acne. The Cochrane Database of Systematic Reviews 2004 , issue 3

12 Strauss JS, Cunningham WJ, Leyden JJ, et al. Isotretinoin and teratogenicity. $J$ Am Acad Dermatol 1983;19:353-4.

13 Goodfield M, Cox N, Dudley A, et al. on behalf of the Retinoid Working Party. Advice on the safe introduction and continued use of isotretinoin in acne. British Association of Dermatologists clinical guidelines 2003

14 Cunliffe WJ. Acne. Textbook of pediatric dermatology. Blackwell Science, 2000.

15 Cunliffe WJ, Baron SE, Coulson IH. A clinical and therapeutic study of 29 patients with infantile acne. Br J Dermatol 2001;145:463-6.

16 Dreno B, Moyse D, Alirezani M, et al. Multicentre randomised comparative double-blind controlled clinical trial of the safety and efficacy of zinc gluconate versus minocycline hydrochloride in the treatment of inflammatory acne vulgaris. Dermatology 2001;203:135-40.

17 Seaton ED, Charakida A, Mouser PE, et al. Pulsed-dye laser treatment for inflammatory acne vulgaris: randomised controlled trial. Lancet 2003;362:1347-52. 